\title{
Glucosamine-containing supplement improves locomotor functions in subjects with knee pain: a randomized, double-blind, placebo-controlled
} study

\author{
Noriyuki Kanzaki ${ }^{1}$ \\ Yoshiko Ono' \\ Hiroshi Shibatal \\ Toshio Moritani² \\ 'Institute for Health Care Science, \\ Suntory Wellness Ltd, Seika-cho, \\ Soraku-gun, ${ }^{2}$ Graduate School of \\ Human and Environmental Studies, \\ Kyoto University, Sakyo-ku, Kyoto, \\ Japan
}

\author{
This article was published in the following Dove Press journal: \\ Clinical Interventions in Aging \\ 28 October 2015 \\ Number of times this article has been viewed
}

Background: The aim of this study was to investigate the ability of a glucosamine-containing supplement to improve locomotor functions in subjects with knee pain.

Methods: A randomized, double-blind, placebo-controlled, parallel-group comparative study was conducted for 16 weeks in 100 Japanese subjects (age, $51.8 \pm 0.8$ years) with knee pain. Subjects were randomly assigned to one of the two supplements containing 1) 1,200 mg of glucosamine hydrochloride, $60 \mathrm{mg}$ of chondroitin sulfate, $45 \mathrm{mg}$ of type II collagen peptides, $90 \mathrm{mg}$ of quercetin glycosides, $10 \mathrm{mg}$ of imidazole peptides, and $5 \mu \mathrm{g}$ of vitamin D per day (GCQID group, $\mathrm{n}=50$ ) or 2) a placebo (placebo group, $n=50$ ). Japanese Knee Osteoarthritis Measure, visual analog scale score, normal walking speed, and knee-extensor strength were measured to evaluate the effects of the supplement on knee-joint functions and locomotor functions.

Results: In subjects eligible for efficacy assessment, there was no significant group $\times$ time interaction, and there were improvements in knee-joint functions and locomotor functions in both groups, but there was no significant difference between the groups. In subjects with mildto-severe knee pain at baseline, knee-extensor strength at week 8 (104.6 $\pm 5.0 \%$ body weight vs $92.3 \pm 5.5 \%$ body weight, $P=0.030)$ and the change in normal walking speed at week 16 $(0.11 \pm 0.03 \mathrm{~m} / \mathrm{s}$ vs $0.05 \pm 0.02 \mathrm{~m} / \mathrm{s}, P=0.038)$ were significantly greater in the GCQID group than in the placebo group. Further subgroup analysis based on Kellgren-Lawrence $(\mathrm{K}-\mathrm{L})$ grade showed that normal walking speed at week $16(1.36 \pm 0.05 \mathrm{~m} / \mathrm{s}$ vs $1.21 \pm 0.02 \mathrm{~m} / \mathrm{s}, P<0.05)$ was significantly greater in the GCQID group than in the placebo group in subjects with $\mathrm{K}-\mathrm{L}$ grade I. No adverse effect of treatment was identified in the safety assessment.

Conclusion: In subjects with knee pain, GCQID supplementation was effective for relieving knee pain and improving locomotor functions.

Keywords: normal walking speed, knee-extensor strength, quercetin glycosides, imidazole peptides, vitamin D

\section{Introduction}

In Japan, people aged 65 years and older comprise $>21 \%$ of the population, and the nation is becoming a super-aged society more rapidly than any other country. In 2007 , the Japanese Orthopaedic Association (JOA) proposed the concept of "locomotive syndrome", which refers to those elderly individuals who require nursing-care services because of problems with the locomotor organs or because they are at risk for conditions for which they may need such services in the future. ${ }^{1}$ Locomotive syndrome is caused mainly by age-related locomotor organ diseases such as osteoporosis and osteoarthritis
Correspondence: Noriyuki Kanzaki Institute for Health Care Science, Suntory Wellness Ltd, 8-I-I Seikadai, Seika-cho, Soraku-gun, Kyoto 619-0284, Japan

Tel $+8 \mid 5031820666$

$\mathrm{Fax}+81774986262$

Email noriyuki_kanzaki@suntory.co.jp 
(OA) or age-related locomotor dysfunctions such as decline in walking speed and loss of muscle strength., ${ }^{2,3}$

$\mathrm{OA}$ is the most common joint disease, which causes pain in elderly patients. The knee is most frequently affected by $\mathrm{OA}$ because it is a weight-bearing joint, and knee OA impairs locomotor functions such as walking speed. ${ }^{4}$ According to the Research on Osteoarthritis Against Disability (ROAD) study, $>25$ million Japanese people aged 40 years and older have been estimated to have radiographically determined Kellgren-Lawrence (K-L) grade II or higher joint-space narrowing. ${ }^{5,6}$ Previous studies reported that walking speed was associated with survival in older adults and that muscle weakness is the highest risk factor for falling, which can result in being bedridden. ${ }^{78}$ Therefore, preventing these locomotor dysfunctions is considered essential to maintain quality of life.

We previously demonstrated that an orally administered supplement containing glucosamine hydrochloride, chondroitin sulfate, and quercetin glycosides (GCQ) was effective for relieving knee pain..$^{9,10}$ Supplements containing glucosamine and chondroitin sulfate have been widely used for the management of knee pain in OA. ${ }^{11-13}$ Nonsteroidal anti-inflammatory drugs (NSAIDs) relieve knee pain associated with $\mathrm{OA}$ and improve locomotor functions in patients with knee OA. ${ }^{14}$ These facts led us to speculate that glucosamine-containing supplements, as well as NSAIDs, could contribute to improved locomotor functions such as knee-extensor strength and walking speed.

Quercetin, one of the flavonoids, which is widely distributed in plants and fruits, has been reported to suppress the atrophy of skeletal muscle in vivo. ${ }^{15}$ Imidazole peptides are distributed mainly in the muscles of animals and have been reported to attenuate muscle fatigue in humans. ${ }^{16}$ Furthermore, vitamin $\mathrm{D}$ is a nutrient that supports bone metabolism, and several studies have demonstrated its benefit in maintaining musculoskeletal functions and reducing the risk of falls in the elderly. ${ }^{17,18}$

In the present study, we investigated the effects of 16 weeks of treatment with a supplement containing glucosamine hydrochloride, chondroitin sulfate, type II collagen peptides, quercetin glycosides, imidazole peptides, and vitamin D (GCQID) on locomotor functions in subjects with knee pain.

\section{Methods}

\section{Study design and participants}

A randomized, double-blind, placebo-controlled, parallelgroup comparative study was designed to assess the efficacy and safety of GCQID supplementation in Japanese women and men aged 40-74 years. Inclusion criteria were the presence of knee pain, confirmed using the walking subscale of the JOA criteria ( $\leq 25$ points for either the left or right knee joint); ${ }^{19}$ visual analog scale (VAS) score for knee pain ( $\geq 20 \mathrm{~mm}$ using the first (I) item of the Japanese Knee Osteoarthritis Measure [JKOM]); ${ }^{20}$ and K-L grades 0-II. ${ }^{5}$ All participants received an explanation about the study from the medical investigators, and written informed consent was obtained prior to enrollment in the study. Exclusion criteria were the following: faster walking speed $(\geq 1.6 \mathrm{~m} / \mathrm{s})$; presence of hyperuricemia, diabetes, cardiovascular disease, hepatic disease, renal disease, or heart disease; treatment with exercise, diet, or medicine that may have an effect on the weight; presence of rheumatic arthritis that may cause joint pain; surgical treatment of knee joint(s) undergone or its necessity; needs to undergo pharmacological articular treatments during the study period; intra-articular hyaluronic acid within 2 weeks or corticosteroids within 3 months before inclusion; a history of osseous or articular diseases other than OA within the past 3 months; routine use of health food or medicine that may have an effect on the evaluation of the study; daily use of a cane; performing daily or occasional vigorous exercise; treatment with warfarin; bronchial asthma, respiratory disease, or potential for developing allergy to the test supplement; pregnant women; nursing mothers or women of child-bearing potential; and presence of any medical condition judged by the medical investigator.

One hundred participants were enrolled in the study, which was performed from February 2012 to September 2012 at a clinical services center in Japan. All subjects, who had never taken the same or similar type of supplement before, were recruited in and around Osaka, Kyoto, Japan, through a volunteer bank managed by HUMA R\&D Co, Inc. (Tokyo, Japan). Once radiographs were obtained, each subject's K-L grade was determined by an orthopedic surgeon. The study protocol was approved by the institutional ethics committee of East One Medical Clinic (Tokyo, Japan) and was conducted in accordance with the principles of the amended Declaration of Helsinki and Ethical Guidelines for Epidemiological Research (issued by the Japanese government in 2008).

\section{Treatment and group assignment}

The GCQID contained 1,200 mg of glucosamine hydrochloride, $300 \mathrm{mg}$ of shark cartilage extract $(60 \mathrm{mg}$ as chondroitin sulfate, $45 \mathrm{mg}$ as type II collagen peptides), $90 \mathrm{mg}$ of quercetin glycosides, $100 \mathrm{mg}$ of fish meat extract $(10 \mathrm{mg}$ 
as imidazole peptides [anserine and carnosine]), and $5 \mu \mathrm{g}$ (200 IU) of vitamin D in eight tablets. Placebo just contained base material such as dextrin, and it did not contain components such as glucosamine hydrochloride, chondroitin sulfate, type II collagen peptides, quercetin glycosides, imidazole peptides, and vitamin D in eight tablets. Subjects were randomly distributed to the two treatment groups in terms of normal walking speed, age, sex, average steps walked in a week, body mass index, and the aggregate scores for the JOA criteria and sequentially assigned to receive either GCQID (GCQID group) or placebo (placebo group). The randomization codes for enrolled subjects were held by an appointed person who was not involved in the study. The GCQID and placebo tablets were manufactured by Suntory Wellness Ltd specifically for the purpose of the present study to ensure that the placebo tablet was indistinguishable from the GCQID tablet in appearance, taste, and packaging. Allocation was preassigned on the basis of randomization numbers and was concealed from the subjects, the investigators, and the researchers who recruited and assessed participating subjects. All subjects were instructed to take eight tablets once a day and to record in their study diary whether they took the tablets or not.

\section{Efficacy assessment}

The efficacy of GCQID supplementation was assessed on the basis of measures of knee-joint functions and locomotor functions. Data on knee-joint functions were collected at baseline and at weeks 4, 8, 12, and 16. Data on locomotor functions were collected at baseline and at weeks 8 and 16. Serum 25-hydroxy vitamin D (25-OHD) levels were measured at baseline and week 16 as an assessment of efficacy. Exclusion criteria based on efficacy assessment were as follows: taking $<80 \%$ of the test supplement, performing actions that affected the reliability of the efficacy assessment (subjects who had too great a difference $[\geq \pm 0.25 \mathrm{~m} / \mathrm{s}]$ in measured walking speed between the screening period and baseline), and noncompliance with the clinical protocol.

Knee-joint functions were measured as score for JKOM item I (VAS score for JKOM knee pain), total score for JKOM items II-V (JKOM total score), ${ }^{20}$ and VAS score for pain on walking. VAS score was measured on a scale from 0 to 100 , where 0 indicated no pain and 100 indicated the worst pain ever experienced. Subjects self-reported these measures on a website available only to the study participants. JKOM total score is a self-administered, disease-specific measure, consisting of 25 items that cover four different categories: "II: pain and stiffness in knees", "III: conditions in daily life", "IV: general activities", and "V: health conditions". An overall result was assessed by summing the scores from the 25 items, with results ranging from 0 (no complaint) to 100 (most severe condition possible).

Locomotor functions were measured as walking speed and knee-extensor strength. For the measurement of walking speed, subjects were instructed to walk $10 \mathrm{~m}$ two times at their usual speed. The time it took to walk the intermediate $6 \mathrm{~m}$ was measured, and the average of two times was calculated as a subject's walking speed. We measured the knee-extensor strength (torque) using a procedure previously described. ${ }^{21}$ For the measurement of knee-extensor strength, subjects performed isometric knee extensions on a custom dynamometer mounted force transducer (LU-100KSE; Kyowa Electronic Instruments, Tokyo, Japan). During the contraction of muscle, both knee joint and hip angles were flexed at $90^{\circ}\left(180^{\circ}\right.$ was fully extended). For the maximal voluntary contractions of subjects, knee extension force exerted by knee extensor muscles was gradually increased from baseline to maximum in 2-3 seconds and then sustained at maximum for 2 seconds. Subjects carried out three trials with each leg, and the highest of the three was used. The sum of the values for both legs per unit body weight represented knee-extensor strength. The number of steps walked weekly, performed in leisurely fashion, and associated with activities of daily living was monitored using a pedometer.

A stratified analysis of subjects with mild-to-severe knee pain (VAS score for JKOM knee pain $\geq 20$ at baseline) was also performed. Using the OA criteria from the ROAD study, ${ }^{6}$ subgroups with or without radiographic OA (K-L grade $\geq$ II or $\leq \mathrm{I}$, respectively) were then analyzed further.

\section{Safety assessment}

The safety of GCQID supplementation was assessed on the basis of the incidence and severity of treatment-related adverse events reported throughout the 16-week intervention period. Furthermore, enrolled subjects were requested to visit a clinic to undergo laboratory tests (hematology, blood biochemistry, and urinalysis) and physical examinations at baseline and week 16 as part of the safety assessment. Blood samples were obtained with the subjects in a fasting state, and urine samples from the morning's second void were collected.

\section{Statistical analysis}

All data are expressed as mean \pm standard error unless otherwise specified. Baseline data were compared between the groups using the unpaired $t$-test for quantitative variables and 
$\chi^{2}$-test for qualitative variables. Two-way repeated-measures analysis of variance was used for analyzing the differences in the effect of intervention, and post hoc analysis was conducted. In case of no significant group $\times$ time interaction, comparisons between groups at each time point were performed using the Mann-Whitney $U$-test for JKOM total score and the unpaired $t$-test for physical and laboratory test variables, VAS score for JKOM knee pain, VAS score for pain on walking, normal walking speed, and knee-extensor strength. For reference, changes in measurements during the intervention were compared with baseline using a paired $t$-test for physical and laboratory test variables; the Steel test for JKOM total score; and Dunnett's test for VAS score for JKOM knee pain, VAS score for pain on walking, normal walking speed, and knee-extensor strength. $P$-values $<0.05$ were considered significant. Effect sizes ( $d$ values for parametric variables and $r$ values for nonparametric variables) were calculated in the measures in which there were significant differences between the groups. All statistical analyses were carried out using IBM SPSS Statistics for Windows, Version 21.0 (IBM Corporation, Armonk, NY, USA) and Ekuseru-Toukei 2010 for Windows (Social Survey Research Information Co, Ltd, Tokyo, Japan).

\section{Results}

Table 1 presents the baseline characteristics for all enrolled subjects. No significant difference was observed between the groups for any characteristic. The 100 subjects who took the test supplement were eligible for safety assessment.
Three subjects dropped out of the study because of adverse events (GCQID: 1, placebo: 1) or personal reasons (GCQID: 1), and 15 subjects were excluded from efficacy assessment because of efficacy-assessment exclusion criteria: taking $<80 \%$ of the test supplement (GCQID: 1 ); performing actions that affected the reliability of the efficacy assessment (too great a difference $[\geq \pm 0.25 \mathrm{~m} / \mathrm{s}]$ in measured walking speed between the screening period and baseline) (GCQID: 1, placebo: 2); and noncompliance with the clinical protocol (GCQID: 5, placebo: 6). Thus, 41 subjects in the GCQID group and 41 in the placebo group were deemed eligible for efficacy assessment.

Table 2 shows the changes in knee-joint functions and locomotor functions during the 16-week intervention period. There was no significant group $\times$ time interaction in all measures for efficacy assessment. There was no significant difference between the groups in all measures for efficacy assessment except for serum 25-OHD levels. Serum 25-OHD levels were significantly greater in the GCQID group than in the placebo group at week $16(31.9 \pm 0.8 \mathrm{ng} / \mathrm{mL}$ vs $28.5 \pm 1.1 \mathrm{ng} / \mathrm{mL}, P<0.05, d=0.49)$.

A stratified analysis of subjects with mild-to-severe knee pain (VAS score for JKOM knee pain $\geq 20$ at baseline) was performed. No significant difference was observed between the groups for any characteristic (Table 3 ). There was no significant group $\times$ time interaction in all measures for efficacy assessment except for serum 25-OHD levels, and knee-extensor strength was significantly greater in the GCQID group than in the placebo group at week $8(P<0.05, d=0.65$; Table 4$)$.

Table I The baseline characteristics of the study population

\begin{tabular}{|c|c|c|c|}
\hline Variables & $\begin{array}{l}\text { GCQID group }^{a} \\
(n=50)\end{array}$ & $\begin{array}{l}\text { Placebo group } \\
(n=50)\end{array}$ & $P$-value \\
\hline Age (years) & $51.9 \pm 1.2$ & $5 \mathrm{I} .6 \pm \mathrm{I} . \mathrm{I}$ & 0.852 \\
\hline Sex (male/female) & $22 / 28$ & $22 / 28$ & 1.000 \\
\hline Height $(\mathrm{cm})$ & $162.0 \pm 1.0$ & $163.0 \pm 1.2$ & 0.507 \\
\hline Body weight (kg) & $60.3 \pm 1.3$ & $62.3 \pm 1.3$ & 0.397 \\
\hline Body mass index $\left(\mathrm{kg} / \mathrm{m}^{2}\right)$ & $22.9 \pm 0.5$ & $23.3 \pm 0.5$ & 0.500 \\
\hline Systolic blood pressure $(\mathrm{mmHg})$ & $129.7 \pm 2.1$ & $125.7 \pm 2.2$ & 0.198 \\
\hline Diastolic blood pressure $(\mathrm{mmHg})$ & $8 I .1 \pm 1.5$ & $80.2 \pm 1.5$ & 0.704 \\
\hline Heart rate (beats/min) & $71.8 \pm 1.6$ & $75.4 \pm 1.7$ & 0.131 \\
\hline Normal walking speed $(\mathrm{m} / \mathrm{s})$ & $1.28 \pm 0.02$ & $1.29 \pm 0.02$ & 0.912 \\
\hline Knee-extensor strength (\% body weight $)^{b}$ & $100.0 \pm 5.2$ & $93.1 \pm 5.3$ & 0.360 \\
\hline JOA criteria aggregate scores (points) & $\mid 80.4 \pm 1.3$ & $177.9 \pm 2.0$ & 0.919 \\
\hline VAS score for pain on walking $(\mathrm{mm})$ & $25.5 \pm 3.0$ & $21.3 \pm 2.7$ & 0.297 \\
\hline Average daily steps walked in a week (steps) & $6,511 \pm 465$ & $6,192 \pm 446$ & 0.622 \\
\hline $\mathrm{K}-\mathrm{L}$ grades $(0, \mathrm{I}, \mathrm{II})$ & $|4,25,1|$ & $16,23,11$ & 0.897 \\
\hline
\end{tabular}

Notes: ${ }^{a} \mathrm{All}$ values except sex and $\mathrm{K}-\mathrm{L}$ grade are expressed as mean \pm standard error. ${ }^{\mathrm{b}} \mathrm{Knee-extensor}$ strength was measured in both knees and expressed as total strength of both knees.

Abbreviations: GCQID, glucosamine hydrochloride, chondroitin sulfate, type II collagen peptides, quercetin glycosides, imidazole peptides, and vitamin D; JOA, Japanese Orthopaedic Association; K-L, Kellgren-Lawrence; VAS, visual analog scale. 
Table 2 Changes in knee-joint functions and locomotor functions in subjects eligible for efficacy assessment ${ }^{\mathrm{a}}$

\begin{tabular}{|c|c|c|c|c|c|c|}
\hline \multirow[t]{2}{*}{ Variables } & \multicolumn{5}{|c|}{ Values at each time point ${ }^{b}$} & \multirow{2}{*}{$\begin{array}{l}\text { Two-way ANOVA } \\
\text { (group } \times \text { time) } \\
P \text {-value }\end{array}$} \\
\hline & Baseline & Week 4 & Week 8 & Week 12 & Week 16 & \\
\hline \multicolumn{7}{|l|}{ JKOM } \\
\hline \multicolumn{7}{|c|}{ (I) VAS score for knee pain (mm) } \\
\hline GCQID & $27.0 \pm 3.4$ & $24.2 \pm 3.1$ & $|7.| \pm 2.5^{*}$ & $14.0 \pm 3.0 * *$ & $9.8 \pm 2.3 * *$ & \multirow[t]{2}{*}{0.939} \\
\hline Placebo & $28.5 \pm 3.0$ & $24.2 \pm 3.3$ & $18.7 \pm 3.2 *$ & $13.0 \pm 2.5^{* *}$ & $\mid I .4 \pm 2 . I^{* *}$ & \\
\hline \multicolumn{7}{|c|}{ (II-V) Total score (points) } \\
\hline GCQID & $14.0 \pm 1.6$ & $11.8 \pm 1.5$ & $9.2 \pm 1.0 *$ & $9.1 \pm 1.2^{* *}$ & $8.5 \pm 1.1 * *$ & \multirow[t]{2}{*}{0.362} \\
\hline Placebo & $13.0 \pm 1.0$ & $12.6 \pm 1.1$ & 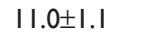 & $10.5 \pm 1.2$ & $9.3 \pm 0.9 *$ & \\
\hline \multicolumn{7}{|c|}{ VAS score for pain on walking (mm) } \\
\hline GCQID & $23.7 \pm 3.3$ & $16.2 \pm 2.8$ & $12.5 \pm 2.5^{* *}$ & $9.6 \pm 2.3 * *$ & $7.1 \pm 2.2 * *$ & \multirow[t]{2}{*}{0.216} \\
\hline Placebo & $18.6 \pm 2.2$ & $16.1 \pm 2.9$ & $|5.0 \pm 3|$. & $11.6 \pm 2.3^{*}$ & $7.3 \pm 1.6 * *$ & \\
\hline \multicolumn{7}{|c|}{ Normal walking speed $(\mathrm{m} / \mathrm{s})$} \\
\hline GCQID & $1.28 \pm 0.03$ & & $1.32 \pm 0.03 *$ & & $1.35 \pm 0.02 * *$ & \multirow[t]{2}{*}{0.524} \\
\hline Placebo & $1.28 \pm 0.02$ & & $1.32 \pm 0.02 *$ & & $1.33 \pm 0.02 * *$ & \\
\hline \multicolumn{7}{|c|}{ Knee-extensor strength (\% body weight $)^{c}$} \\
\hline GCQID & $95.9 \pm 5.0$ & & $104.6 \pm 5.0 *$ & & $104.5 \pm 4.9 *$ & \multirow[t]{2}{*}{0.546} \\
\hline Placebo & $88.1 \pm 5.8$ & & $92.3 \pm 5.5$ & & $92.6 \pm 5.6$ & \\
\hline
\end{tabular}

Notes: a GCQID group $(n=4 I)$ and placebo group $(n=4 I)$. ${ }^{b}$ Values expressed as mean \pm standard error. ${ }^{c}$ Knee-extensor strength was measured in both knees and expressed as the total strength of both knees. $* P<0.05$ and $* * P<0.01$ compared with baseline value.

Abbreviations: ANOVA, analysis of variance; GCQID, glucosamine hydrochloride, chondroitin sulfate, type II collagen peptides, quercetin glycosides, imidazole peptides, and vitamin D; JKOM, Japanese Knee Osteoarthritis Measure; VAS, visual analog scale.

The change in JKOM total score at week $8(P<0.05, r=0.37)$ and the change in normal walking speed at week $16(P<0.05$, $d=0.62$ ) were significantly greater in the GCQID group than in the placebo group (Figure 1). There was a significant group $\times$ time interaction in serum 25-OHD levels, and the change in serum 25-OHD levels at week 16 was significantly greater in the GCQID group than in the placebo group $(11.9 \pm 1.8 \mathrm{ng} / \mathrm{mL}$ vs $6.9 \pm 1.3 \mathrm{ng} / \mathrm{mL}, P<0.05, d=0.80)$.
Subgroup analysis based on $\mathrm{K}-\mathrm{L}$ grade in subjects with mild-to-severe knee pain at baseline was also performed. There was no significant group $\times$ time interaction, and there was no significant difference between the groups in JKOM total score and normal walking speed both in subjects with $\mathrm{K}-\mathrm{L}$ grades $\geq \mathrm{II}$ and in subjects with $\mathrm{K}-\mathrm{L}$ grade $\leq \mathrm{I}$ (Table 5). In subjects with $\mathrm{K}-\mathrm{L}$ grades $\geq \mathrm{II}$, the change in JKOM total score at week 8 was significantly greater in the

Table 3 Baseline characteristics of subjects selected for stratified analyses

\begin{tabular}{|c|c|c|c|}
\hline Variables & $\begin{array}{l}\text { GCQID group }^{a} \\
(n=23)\end{array}$ & $\begin{array}{l}\text { Placebo group } \\
(n=25)\end{array}$ & $P$-value \\
\hline Age (years) & $51.5 \pm 1.7$ & $50.6 \pm 1.4$ & 0.702 \\
\hline Sex (male/female) & $9 / 14$ & $12 / 13$ & 0.536 \\
\hline Height (cm) & $162.3 \pm 1.7$ & $163.8 \pm 1.7$ & 0.527 \\
\hline Body weight (kg) & $63.1 \pm 2.8$ & $62.9 \pm 2.3$ & 0.956 \\
\hline Body mass index $\left(\mathrm{kg} / \mathrm{m}^{2}\right)$ & $23.8 \pm 0.7$ & $23.4 \pm 0.7$ & 0.696 \\
\hline Systolic blood pressure (mmHg) & $131.1 \pm 3.6$ & $126.6 \pm 3.2$ & 0.352 \\
\hline Diastolic blood pressure $(\mathrm{mmHg})$ & $82.7 \pm 2.5$ & $82.4 \pm 2.5$ & 0.924 \\
\hline Heart rate (beats/min) & $72.0 \pm 2.3$ & $76.7 \pm 2.3$ & 0.153 \\
\hline Normal walking speed $(\mathrm{m} / \mathrm{s})$ & $1.26 \pm 0.04$ & $1.25 \pm 0.03$ & 0.957 \\
\hline Knee-extensor strength (\% body weight $)^{\mathrm{b}}$ & $93.4 \pm 6.7$ & $81.5 \pm 7.6$ & 0.248 \\
\hline JOA criteria aggregate scores (points) & $178.9 \pm 2.0$ & $175.4 \pm 2.9$ & 0.522 \\
\hline VAS score for pain on walking (mm) & $33.3 \pm 4.3$ & $24.5 \pm 3.0$ & 0.103 \\
\hline Average daily steps walked in a week (steps) & $6,221 \pm 510$ & $6,386 \pm 599$ & 0.837 \\
\hline $\mathrm{K}-\mathrm{L}$ grades $(0, \mathrm{I}, \mathrm{II})$ & $6,14,3$ & $7,12,6$ & 0.563 \\
\hline
\end{tabular}

Notes: aAll values except sex and $\mathrm{K}-\mathrm{L}$ grade are expressed as mean \pm standard error. ${ }^{\mathrm{b}} \mathrm{Knee-extensor}$ strength was measured in both knees and expressed as total strength of both knees.

Abbreviations: GCQID, glucosamine hydrochloride, chondroitin sulfate, type II collagen peptides, quercetin glycosides, imidazole peptides, and vitamin D; JOA, Japanese Orthopaedic Association; K-L, Kellgren-Lawrence; VAS, visual analog scale. 
Table 4 Changes in knee-joint functions and locomotor functions at each time point in subjects with mild-to-severe knee pain at baseline $^{\mathrm{a}}$

\begin{tabular}{|c|c|c|c|c|c|c|}
\hline \multirow[t]{2}{*}{ Variables } & \multicolumn{5}{|c|}{ Values at each time point ${ }^{\mathrm{b}}$} & \multirow{2}{*}{$\begin{array}{l}\text { Two-way ANOVA } \\
\text { (group } \times \text { time) } \\
\text { P-value }\end{array}$} \\
\hline & Baseline & Week 4 & Week 8 & Week I2 & Week I6 & \\
\hline \multicolumn{7}{|l|}{ JKOM } \\
\hline \multicolumn{7}{|c|}{ (I) VAS score for knee pain (mm) } \\
\hline GCQID & $41.5 \pm 4.0$ & $31.2 \pm 4.3$ & $19.9 \pm 2.9 * *$ & $15.4 \pm 4.4 * *$ & $9.9 \pm 3.4^{* *}$ & \multirow[t]{2}{*}{0.490} \\
\hline Placebo & $40.0 \pm 3.1$ & $28.6 \pm 3.9 *$ & $22.4 \pm 3.5 * *$ & $18.5 \pm 3.7 * *$ & $16.4 \pm 3.0 * *$ & \\
\hline \multicolumn{7}{|c|}{ (II-V) Total score (points) } \\
\hline GCQID & $17.6 \pm 2.5$ & $14.3 \pm 2.5$ & $10.3 \pm 1.5^{*}$ & $10.7 \pm 2.0 * *$ & $9.2 \pm 1.7^{* *}$ & \multirow[t]{2}{*}{0.169} \\
\hline Placebo & $15.2 \pm 1.3$ & $13.7 \pm 1.6$ & $13.3 \pm 1.6$ & $12.2 \pm 1.7$ & $10.6 \pm 1.2$ & \\
\hline \multicolumn{7}{|c|}{ VAS score for pain on walking $(\mathrm{mm})$} \\
\hline GCQID & $33.3 \pm 4.3$ & $22.2 \pm 4.3^{*}$ & $14.3 \pm 3.4^{* *}$ & $12.0 \pm 3.9 * *$ & $8.7 \pm 3.8^{* *}$ & \multirow[t]{2}{*}{0.067} \\
\hline Placebo & $24.5 \pm 3.0$ & $20.0 \pm 3.7$ & $17.9 \pm 3.4^{*}$ & $16.6 \pm 3.4^{*}$ & $9.6 \pm 2.4^{* *}$ & \\
\hline \multicolumn{7}{|c|}{ Normal walking speed $(\mathrm{m} / \mathrm{s})$} \\
\hline GCQID & $1.26 \pm 0.04$ & & $1.32 \pm 0.04 *$ & & $1.37 \pm 0.04 * *$ & \multirow[t]{2}{*}{0.095} \\
\hline Placebo & $1.25 \pm 0.03$ & & $1.28 \pm 0.03$ & & $1.30 \pm 0.03 *$ & \\
\hline \multicolumn{7}{|c|}{ Knee extensor strength (\% body weight) ${ }^{c}$} \\
\hline GCQID & $93.4 \pm 6.7$ & & $108.4 \pm 5.3 * *, 8$ & & $109.8 \pm 5.6 * *$ & \multirow[t]{2}{*}{0.330} \\
\hline Placebo & $81.5 \pm 7.6$ & & $88.0 \pm 7.3$ & & $92.0 \pm 7.8 * *$ & \\
\hline
\end{tabular}

Notes: aGCQID group ( $\mathrm{n}=23)$ and placebo group $(\mathrm{n}=25)$. ${ }^{\mathrm{b}} \mathrm{Values}$ are expressed as mean \pm standard error. ${ }^{\mathrm{C} K n e e-e x t e n s o r}$ strength was measured in both knees and expressed as total strength of both knees. $* P<0.05$ and $* * P<0.01$ compared with values at baseline. ${ }^{\$} P<0.05$ compared with placebo.

Abbreviations: ANOVA, analysis of variance; GCQID, glucosamine hydrochloride, chondroitin sulfate, type II collagen peptides, quercetin glycosides, imidazole peptides, and vitamin D; JKOM, Japanese Knee Osteoarthritis Measure; VAS, visual analog scale.

GCQID group than in the placebo group $(-20.3 \pm 12.5$ points vs $0.5 \pm 1.5$ points, $P<0.05, r=0.74)$. The change in normal walking speed tended to be greater in the GCQID group than in the placebo group at week 16, but the difference was not significant $(P=0.08)$. Similarly, in subjects with $\mathrm{K}-\mathrm{L}$ grade $\leq \mathrm{I}$, the change in normal walking speed tended to be greater in the GCQID group than in the placebo group at week $16(P=0.08)$.

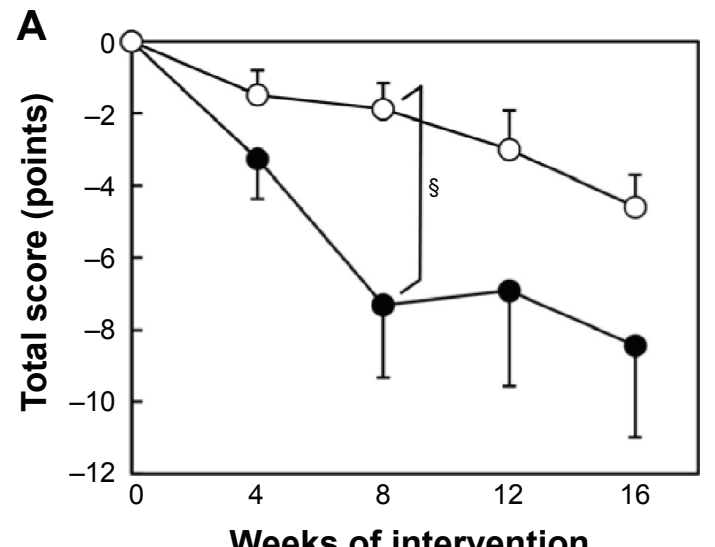

Weeks of intervention
Further analysis of subjects with $\mathrm{K}-\mathrm{L}$ grade I (14 in the GCQID group and 12 in the placebo group) showed that there was no significant group $\times$ time interaction in JKOM total score and normal walking speed, and the change in JKOM total score was significantly greater in the GCQID group than in the placebo group at week $8(-6.2 \pm 1.5$ points vs $-1.8 \pm 0.9$ points, $P<0.05, r=0.42$ ). Normal walking speed in the GCQID group was significantly greater than in the placebo

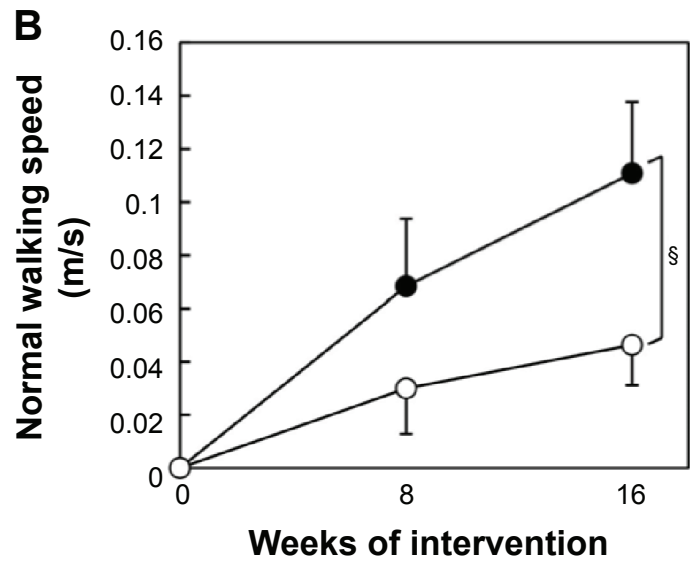

GCQID $-0-$ Placebo

Figure I Changes in magnitude of (A) JKOM total score (items II-V) and (B) normal walking speed.

Notes: GCQID group $(n=23)$ and placebo group $(n=25) .{ }^{\$} P<0.05$ compared with placebo group. Values are expressed as mean \pm standard error.

Abbreviations: GCQID, glucosamine hydrochloride, chondroitin sulfate, type Il collagen peptides, quercetin glycosides, imidazole peptides, and vitamin D; JKOM, Japanese Knee Osteoarthritis Measure. 
Table 5 Changes in JKOM total score (items II-V) and normal walking speed at each time point in subjects with mild-to-severe knee pain and baseline $\mathrm{K}-\mathrm{L}$ grade $\geq \mathrm{II}$ or $\leq \mathrm{I}^{\mathrm{a}}$

\begin{tabular}{|c|c|c|c|c|c|c|c|c|}
\hline \multirow{3}{*}{$\begin{array}{l}\text { Variables } \\
\text { Values at each } \\
\text { time point }^{\mathrm{b}}\end{array}$} & \multicolumn{4}{|c|}{$\mathrm{K}-\mathrm{L}$ grades $\geq \mathrm{II}$} & \multicolumn{4}{|c|}{ K-L grades $\leq$ I } \\
\hline & \multicolumn{2}{|c|}{$\begin{array}{l}\text { JKOM total score } \\
\text { (points) }\end{array}$} & \multicolumn{2}{|c|}{$\begin{array}{l}\text { Normal walking speed } \\
(\mathrm{m} / \mathrm{s})\end{array}$} & \multicolumn{2}{|c|}{$\begin{array}{l}\text { JKOM total score } \\
\text { (points) }\end{array}$} & \multicolumn{2}{|c|}{$\begin{array}{l}\text { Normal walking speed } \\
(\mathrm{m} / \mathrm{s})\end{array}$} \\
\hline & GCQID & Placebo & GCQID & Placebo & GCQID & Placebo & GCQID & Placebo \\
\hline Baseline & $29.7 \pm 14.8$ & $13.7 \pm 2.6$ & $1.16 \pm 0.07$ & $1.28 \pm 0.04$ & $15.8 \pm 1.8$ & $15.7 \pm 1.5$ & $1.27 \pm 0.04$ & $1.25 \pm 0.04$ \\
\hline Week 4 & $24.3 \pm 14.9$ & $12.0 \pm 3.4$ & & & $12.9 \pm 2.0$ & $14.3 \pm 2.0$ & & \\
\hline Week 8 & $9.3 \pm 2.4$ & $14.2 \pm 3.8$ & $1.31 \pm 0.13$ & $1.30 \pm 0.05$ & $10.5 \pm 1.7$ & $13.1 \pm 1.8$ & $1.33 \pm 0.05$ & $1.28 \pm 0.04$ \\
\hline Week 12 & $9.3 \pm 1.5$ & $13.0 \pm 5.3$ & & & $10.9 \pm 2.3$ & $11.9 \pm 1.6$ & & \\
\hline Week 16 & $8.0 \pm 2.6$ & $9.3 \pm 2.8$ & $1.35 \pm 0.08$ & $1.35 \pm 0.06^{*}$ & $9.4 \pm 1.9 *$ & $11.0 \pm 1.4$ & $1.37 \pm 0.04 * *$ & $1.28 \pm 0.04$ \\
\hline $\begin{array}{l}\text { Two-way ANOVA } \\
\text { (group } \times \text { time) }\end{array}$ & 0.082 & & 0.064 & & 0.634 & & 0.193 & \\
\hline$P$-value & & & & & & & & \\
\hline
\end{tabular}

group at week $16(1.36 \pm 0.05 \mathrm{~m} / \mathrm{s}$ vs $1.21 \pm 0.02 \mathrm{~m} / \mathrm{s}, P<0.05$, $d=0.68)$. There was no significant difference between the groups in subjects with $\mathrm{K}-\mathrm{L}$ grade 0 (data not shown).

Significant changes in several blood biochemical and hematological variables were observed in both groups during the 16-week intervention (Table S1), but the values were judged by the investigators to have remained within the normal range and to be medically unrelated to the treatment. There were also no abnormal changes in physical parameters and urinalysis, including proteinuria, glucosuria, and hematuria (data not shown). Some subjects in both groups reported experiencing one or more adverse events during the intervention. However, there was no between-group difference in frequency or pattern of events (Table S2). All self-reported adverse events were transient and of mild or intermediate intensity. Moreover, no adverse effect of treatment was identified when these results were analyzed on an individual-subject basis.

\section{Discussion}

The present study was conducted to evaluate effects of a glucosamine-containing supplement (GCQID) on locomotor functions in subjects with knee pain.

The efficacy assessment revealed that GCQID supplementation improved JKOM total score, normal walking speed, and knee-extensor strength in subjects with mild-to-severe knee pain at baseline better than the placebo (Table 4 and Figure 1). Using OA criteria used in the ROAD study, ${ }^{6}$ subgroup analysis based on $\mathrm{K}-\mathrm{L}$ grade was performed to investigate the efficacy of GCQID supplementation with or without radiographic OA. We found that GCQID supplementation only tended to improve normal walking speed more than placebo in subjects with $\mathrm{K}-\mathrm{L}$ grade $\geq \mathrm{II}$ or $\leq \mathrm{I}$, and it significantly improved both JKOM total score and normal walking speed more than placebo in subjects with $\mathrm{K}-\mathrm{L}$ grade I. These results suggest that GCQID supplementation can be effective at improving knee-joint functions and locomotor functions in subjects with mild-to-severe knee pain, especially those with $\mathrm{K}-\mathrm{L}$ grade I joint-space narrowing.

The ability of GCQID supplementation to relieve knee pain may be explained mainly by the anti-inflammatory and chondroprotective activities of glucosamine hydrochloride, ,2,23 $^{22}$ chondroitin sulfate, ${ }^{24}$ and quercetin, ${ }^{25,26}$ as described in a previous study on GCQ supplementation. ${ }^{10}$ Pain signals suppress muscle performance, and knee OA impairs locomotor functions such as walking speed. ${ }^{4}$ Najm et al ${ }^{14}$ showed that NSAIDs improved knee-joint functions and locomotor functions at the same time in patients with knee OA. Similarly, the improvement in knee-joint functions observed with GCQID supplementation in the present study may partially contribute to improved locomotor functions in subjects with knee pain. Mukai et a ${ }^{15}$ confirmed that quercetin can prevent atrophy caused by muscle disuse by attenuating the expression of ubiquitin ligases, and Horii et $\mathrm{al}^{27}$ revealed that a type of imidazole peptide increased muscle blood flow via changes in muscle sympathetic nerve activity, suggesting that quercetin glycosides and imidazole peptides in GCQID can directly affect muscle functions. Lower serum 25-OHD levels are associated with impaired locomotor functions. ${ }^{28}$ The 16-week intervention with GCQID supplementation elevated serum 25-OHD levels compared with the placebo group in subjects with mild-to-severe knee pain, suggesting 
that the elevated serum 25-OHD levels in the GCQID group may partially contribute to improved locomotor functions, although there was a significant group $\times$ time interaction. In Japan, serum 25-OHD levels are lowest at the end of winter and highest at the end of summer, ${ }^{29}$ and the present study was conducted from winter to summer. Therefore, the time effect in elevated serum 25-OHD levels can be partly explained by seasonal changes, which may also partially contribute to improved locomotor functions.

In the present study, GCQID supplementation improved locomotor functions. An increase in muscle strength with GCQID supplementation might be expected to lower the risk of falling because muscle weakness is the highest risk factor for falling. ${ }^{6}$ It has been reported that walking speed is associated with survival in older adults ${ }^{5}$ and that the ingestion of glucosamine or chondroitin is associated with decreased total mortality. ${ }^{30}$ Therefore, GCQID supplementation may have a beneficial effect on survival rate. Further research is needed to elucidate the effect of supplements such as GCQID, which improve locomotor functions, on survival rate.

In the safety assessment, no abnormalities in any laboratory tests were observed and no treatment-related adverse events were experienced during the intervention period, which suggests that GCQID is a safe supplement.

There are some limitations to the present study. First, the study was conducted over a relatively short period and the sample size was relatively small. Therefore, a long-term study with a large sample size may be needed to clarify the effect of GCQID supplementation on locomotor functions. Second, because subjects' daily dietary intake, which might have affected knee-joint functions or locomotor functions, was not monitored, it must be acknowledged that daily diet might have partially affected the efficacy observed in the present study. Third, because the GCQID had several components, further studies should be conducted to clarify the role of each component of the GCQID on locomotor functions.

\section{Conclusion}

In conclusion, our findings suggest that GCQID supplementation was safe and effective in improving knee-joint functions and locomotor functions in subjects with knee pain.

\section{Acknowledgments}

We thank all participants and the professional staff at the Graduate School of Human and Environmental Studies at Kyoto University for their support of the study and Dr Izumo at Suntory Wellness Ltd for his support in the preparation of the manuscript. This research was supported by Suntory Wellness Ltd.

\section{Disclosure}

NK, YO, and HS are employed by Suntory Wellness Ltd, which is the sponsor of this study and markets health food products, such as the GCQID used in this study. Research funding, including travel fees, were provided to TM by Suntory Wellness Ltd. The authors report no other conflicts of interest in this work.

\section{References}

1. Nakamura K. A "super-aged" society and the "locomotive syndrome". J Orthop Sci. 2008;13(1):1-2.

2. Schimpl M, Moore C, Lederer C, et al. Association between walking speed and age in healthy, free-living individuals using mobile accelerometrya cross-sectional study. PLoS One. 2011;6(8):e23299.

3. Lindle RS, Metter EJ, Lynch NA, et al. Age and gender comparisons of muscle strength in 654 women and men aged 20-93 yr. J Appl Physiol. 1997;83(5):1581-1587.

4. Kiss RM. Effect of severity of knee osteoarthritis on the variability of gait parameters. J Electromyogr Kinesiol. 2011;21(5):695-703.

5. Kellgren JH, Lawrence JS. Radiological assessment of osteoarthritis. Ann Rheum Dis. 1957;16(4):494-502.

6. Yoshimura N, Muraki S, Oka H, et al. Prevalence of knee osteoarthritis, lumbar spondylosis, and osteoporosis in Japanese men and women: the research on osteoarthritis/osteoporosis against disability study. J Bone Miner Metab. 2009;27(5):620-628.

7. Studenski S, Perera S, Patel K, et al. Gait speed and survival in older adults. JAMA. 2011;305(1):50-58.

8. American Geriatrics Society, British Geriatrics Society, American Academy of Orthopaedic Surgeons Panel on Falls Prevention. Guideline for the prevention of falls in older persons. J Am Geriatr Soc. 2001;49(5): 664-672.

9. Matsuno H, Nakamura H, Katayama K, et al. Effects of an oral administration of glucosamine-chondroitin-quercetin glucoside on the synovial fluid properties in patients with osteoarthritis and rheumatoid arthritis. Biosci Biotechnol Biochem. 2009;73(2):288-292.

10. Kanzaki N, Saito K, Maeda A, et al. Effect of a dietary supplement containing glucosamine hydrochloride, chondroitin sulfate and quercetin glycosides on symptomatic knee osteoarthritis: a randomized, double-blind, placebo-controlled study. J Sci Food Agric. 2012;92(4):862-869.

11. McAlindon TE, LaValley MP, Gulin JP, Felson DT. Glucosamine and chondroitin for treatment of osteoarthritis: a systematic quality assessment and meta-analysis. JAMA. 2000;283(11):1469-1475.

12. Reginster JY, Deroisy R, Rovati LC, et al. Long-term effects of glucosamine sulphate on osteoarthritis progression: a randomized, placebo-controlled clinical trial. Lancet. 2001;357(9252):251-256.

13. Kahan A, Uebelhart D, De Vathaire F, Delmas PD, Reginster JY. Long-term effects of chondroitins 4 and 6 sulfate on knee osteoarthritis progression prevention: a two-year, randomized, double-blind, placebocontrolled trial. Arthritis Rheum. 2009;60(2):524-533.

14. Najm WI, Reinsch S, Hoehler F, Tobis JS, Harvey PW. S-adenosyl methionine (SAMe) versus celecoxib for the treatment of osteoarthritis symptoms: a double-blind cross-over trial. BMC Musculoskelet Disord. 2004;5:6.

15. Mukai R, Nakao R, Yamamoto H, Nikawa T, Takeda E, Terao J. Quercetin prevents unloading-derived disused muscle atrophy by attenuating the induction of ubiquitin ligases in tail-suspension mice. J Nat Prod. 2010;73(10):1708-1710.

16. Maemura H, Goto K, Yoshioka T, Sato M, Takahata Y, Morimatsu F. Effects of carnosine and anserine supplementation on relatively high intensity endurance performance. Int J Sport Health Sci. 2006;4:86-94. 
17. Bischoff HA, Stähelin HB, Dick W, et al. Effects of vitamin D and calcium supplementation on falls: a randomized controlled trial. J Bone Miner Res. 2003;18(2):343-351.

18. Sato Y, Iwamoto J, Kanoko T, Satoh K. Low-dose vitamin D prevents muscular atrophy and reduces falls and hip fractures in women after stroke: a randomized controlled trial. Cerebrovasc Dis. 2005;20(3):187-192.

19. The Japanese Orthopaedic Association Japanese Knee Society. Assessment Criteria for Knee Diseases and Treatments. Tokyo: Kanehara; 1994.

20. Akai M, Doi T, Fujino K, Iwaya T, Kurosawa H, Nasu T. An outcome measure for Japanese people with knee osteoarthritis. J Rheumatol. 2005;32(8):1524-1532.

21. Watanabe K, Kouzaki M, Merletti R, Fujibayashi M, Moritani T. Spatial EMG potential distribution pattern of vastus lateralis muscle during isometric knee extension in young and elderly men. J Electromyogr Kinesiol. 2012;22(1):74-79.

22. Fenton JI, Chlebek-Brown KA, Peters TL, Caron JP, Orth MW. Glucosamine $\mathrm{HCl}$ reduces equine articular cartilage degradation in explant culture. Osteoarthritis Cartilage. 2000;8(4):258-265.

23. Gouze JN, Bordji K, Gulberti S, et al. Interleukin-1beta down-regulates the expression of glucuronosyltransferase I, a key enzyme priming glycosaminoglycan biosynthesis: influence of glucosamine on interleukin-1beta-mediated effects in rat chondrocytes. Arthritis Rheum. 2001;44(2):351-360.
24. Iovu M, Dumais G, du Souich P. Anti-inflammatory activity of chondroitin sulfate. Osteoarthritis Cartilage. 2008;16(suppl 3):S14-S18.

25. Jackson JK, Higo T, Hunter WL, Burt HM. The antioxidants curcumin and quercetin inhibit inflammatory processes associated with arthritis. Inflamm Res. 2006;55(4):168-175.

26. Mamani-Matsuda M, Kauss T, Al-Kharrat A, et al. Therapeutic and preventive properties of quercetin in experimental arthritis correlate with decreased macrophage inflammatory mediators. Biochem Pharmacol. 2006;72(10):1304-1310.

27. Horii Y, Fujisaki Y, Fuyuki R, Nagai K. L-carnosine's dose-dependent effects on muscle sympathetic nerves and blood flow. Neurosci Lett. 2015; 591:144-148.

28. Suzuki T, Kwon J, Kim H, et al. Low serum 25-hydroxyvitamin D levels associated with falls among Japanese community-dwelling elderly. J Bone Miner Res. 2008;23(8):1309-1317.

29. Ono Y, Suzuki A, Kotake M, et al. Seasonal changes of serum 25-hydroxyvitamin D and intact parathyroid hormone levels in a normal Japanese population. J Bone Miner Metab. 2005;23(2): 147-151.

30. Pocobelli G, Kristal AR, Patterson RE, et al. Total mortality risk in relation to use of less-common dietary supplements. Am J Clin Nutr. 2010; 91(6):1791-1800. 


\section{Supplementary materials}

Table SI Changes in laboratory values between baseline and week 16

\begin{tabular}{|c|c|c|c|}
\hline \multirow[t]{2}{*}{ Variables $^{a}$} & \multirow[t]{2}{*}{ Group } & \multicolumn{2}{|c|}{ Values at time point } \\
\hline & & Baseline & Week 16 \\
\hline \multirow[t]{2}{*}{ AST (IU/L) } & GCQID & $21.3 \pm 0.8$ & $20.6 \pm 0.9$ \\
\hline & Placebo & $22.1 \pm 1.1$ & $19.5 \pm 0.8^{*}$ \\
\hline \multirow[t]{2}{*}{ ALT (IU/L) } & GCQID & $20.7 \pm 1.5$ & $19.7 \pm 2.0$ \\
\hline & Placebo & $22.0 \pm 1.8$ & $20.2 \pm 1.7$ \\
\hline \multirow[t]{2}{*}{ ALP (IU/L) } & GCQID & $204.9 \pm 8.5$ & $201.3 \pm 8.4$ \\
\hline & Placebo & $204.8 \pm 8.2$ & $208.8 \pm 7.6$ \\
\hline \multirow[t]{2}{*}{ LDH (IU/L) } & GCQID & $185.3 \pm 3.9$ & $190.9 \pm 3.8 *$ \\
\hline & Placebo & $184.6 \pm 5.4$ & $187.1 \pm 3.8$ \\
\hline \multirow[t]{2}{*}{$\gamma$-GTP (IU/L) } & GCQID & $30.8 \pm 4.3$ & $29.1 \pm 4.0$ \\
\hline & Placebo & $30.1 \pm 3.4$ & $28.1 \pm 3.4$ \\
\hline \multirow[t]{2}{*}{ T-Bil (mg/dL) } & GCQID & $0.75 \pm 0.05$ & $0.82 \pm 0.05 *$ \\
\hline & Placebo & $0.72 \pm 0.05$ & $0.74 \pm 0.06$ \\
\hline \multirow[t]{2}{*}{$\mathrm{TP}(\mathrm{g} / \mathrm{dL})$} & GCQID & $7.33 \pm 0.05$ & $7.19 \pm 0.05 *$ \\
\hline & Placebo & $7.26 \pm 0.06$ & $7.15 \pm 0.05 *$ \\
\hline \multirow[t]{2}{*}{ Alb (g/dL) } & GCQID & $4.29 \pm 0.03$ & $4.3 I \pm 0.03$ \\
\hline & Placebo & $4.27 \pm 0.04$ & $4.29 \pm 0.03$ \\
\hline \multirow[t]{2}{*}{ CPK (IU/L) } & GCQID & $124.5 \pm 12.6$ & $121.3 \pm 9.9$ \\
\hline & Placebo & $103.0 \pm 6.3$ & $112.7 \pm 7.3$ \\
\hline \multirow[t]{2}{*}{ Triglyceride (mg/dL) } & GCQID & $105.2 \pm 8.0$ & $97.5 \pm 8.4$ \\
\hline & Placebo & $109.2 \pm 9.0$ & $120.0 \pm 11.9$ \\
\hline \multirow[t]{2}{*}{$\mathrm{TC}(\mathrm{mg} / \mathrm{dL})$} & GCQID & $220.7 \pm 4.7$ & $214.3 \pm 4.4$ \\
\hline & Placebo & $223.3 \pm 5.0$ & $213.4 \pm 5.2 * *$ \\
\hline \multirow[t]{2}{*}{ HDL-C (mg/dL) } & GCQID & $68.7 \pm 2.9$ & $65.0 \pm 2.7^{* *}$ \\
\hline & Placebo & $68.2 \pm 2.7$ & $62.5 \pm 2.3 * *$ \\
\hline \multirow[t]{2}{*}{ LDL-C (mg/dL) } & GCQID & $128.3 \pm 3.5$ & $126.0 \pm 3.7$ \\
\hline & Placebo & $130.5 \pm 4.5$ & $125.1 \pm 4.6^{*}$ \\
\hline \multirow[t]{2}{*}{ BUN (mg/dL) } & GCQID & $14.0 \pm 0.5$ & $13.3 \pm 0.6 *$ \\
\hline & Placebo & $13.4 \pm 0.4$ & $13.1 \pm 0.4$ \\
\hline \multirow[t]{2}{*}{ UA (mg/dL) } & GCQID & $4.53 \pm 0.18$ & $4.95 \pm 0.19 * *$ \\
\hline & Placebo & $4.82 \pm 0.16$ & $5.13 \pm 0.17^{* *}$ \\
\hline \multirow[t]{2}{*}{$\mathrm{Cr}(\mathrm{mg} / \mathrm{dL})$} & GCQID & $0.69 \pm 0.02$ & $0.70 \pm 0.02$ \\
\hline & Placebo & $0.66 \pm 0.02$ & $0.68 \pm 0.02 *$ \\
\hline \multirow[t]{2}{*}{$\mathrm{Na}(\mathrm{mEq} / \mathrm{L})$} & GCQID & $\mid 40.1 \pm 0.2$ & $139.9 \pm 0.2$ \\
\hline & Placebo & $140.0 \pm 0.2$ & $140.5 \pm 0.3$ \\
\hline \multirow[t]{2}{*}{$\mathrm{K}(\mathrm{mEq} / \mathrm{L})$} & GCQID & $4.45 \pm 0.05$ & $4.28 \pm 0.05 * *$ \\
\hline & Placebo & $4.48 \pm 0.05$ & $4.26 \pm 0.05 * *$ \\
\hline $\mathrm{Cl}(\mathrm{mEq} / \mathrm{L})$ & GCQID & $103.2 \pm 0.3$ & $103.9 \pm 0.2 *$ \\
\hline & Placebo & $103.3 \pm 0.3$ & $104.2 \pm 0.3 * *$ \\
\hline Glucose (mg/dL) & GCQID & $91.3 \pm 1.5$ & $90.5 \pm 1.8$ \\
\hline & Placebo & $91.4 \pm 1.2$ & $91.3 \pm 1.4$ \\
\hline $\mathrm{HbA}_{\mathrm{lc}}(\%)$ & GCQID & $5.00 \pm 0.05$ & $4.97 \pm 0.05$ \\
\hline & Placebo & $5.07 \pm 0.04$ & $5.06 \pm 0.04$ \\
\hline $\mathrm{CRP}(\mathrm{mg} / \mathrm{dL})^{\mathrm{b}}$ & GCQID & $0.10 \pm 0.02$ & $0.10 \pm 0.02$ \\
\hline & Placebo & $0.10 \pm 0.02$ & $0.07 \pm 0.01$ \\
\hline Insulin $(\mu \mathrm{U} / \mathrm{mL})^{b}$ & GCQID & $5.83 \pm 0.58$ & $5.92 \pm 0.69$ \\
\hline & Placebo & $5.55 \pm 0.65$ & $7.23 \pm 0.84$ \\
\hline WBC $\left(\times 10^{3} / \mu \mathrm{L}\right)$ & GCQID & $5.74 \pm 0.17$ & $5.60 \pm 0.16$ \\
\hline & Placebo & $5.94 \pm 0.20$ & $5.80 \pm 0.19$ \\
\hline $\operatorname{RBC}\left(\times 10^{4} / \mu \mathrm{L}\right)$ & GCQID & $463.1 \pm 4.3$ & $449.0 \pm 4.6 * *$ \\
\hline & Placebo & $466.1 \pm 5.4$ & $454.7 \pm 5.3 * *$ \\
\hline
\end{tabular}


Table SI (Continued)

\begin{tabular}{llll}
\hline Variables $^{\mathbf{a}}$ & Group & \multicolumn{2}{l}{ Values at time point } \\
\cline { 3 - 4 } & & Baseline & Week I6 \\
\hline $\mathrm{Hb}(\mathrm{g} / \mathrm{dL})$ & GCQID & $13.9 \pm 0.2$ & $13.5 \pm 0.2^{* *}$ \\
& Placebo & $14.0 \pm 0.2$ & $13.7 \pm 0.2^{* *}$ \\
$\mathrm{Hct}(\%)$ & GCQID & $42.4 \pm 0.4$ & $41.1 \pm 0.4^{* *}$ \\
& Placebo & $42.8 \pm 0.5$ & $41.5 \pm 0.5^{* *}$ \\
$\mathrm{Plt}\left(\times 10^{4} / \mu \mathrm{L}\right)$ & GCQID & $25.1 \pm 0.9$ & $24.2 \pm 0.9^{*}$ \\
& Placebo & $25.6 \pm 0.9$ & $24.2 \pm 0.8^{* *}$ \\
\hline
\end{tabular}

Notes: All values are expressed as mean \pm standard error for GCQID group $(n=48)$ and placebo group $(n=49)$. ${ }^{a}$ Of the 100 subjects eligible for safety assessment, three (two in the GCQID group and one in the placebo group) dropped out of the study and did not undergo laboratory examinations at week 16 . ${ }^{b} \mathrm{Values}$ below the detectable limit for CRP and insulin are calculated as $0.05 \mathrm{mg} / \mathrm{dL}$ and $2.0 \mu \mathrm{U} / \mathrm{mL}$, respectively. $* P<0.05$ and $* * P<0.0$ I compared with baseline.

Abbreviations: Alb, albumin; ALP, alkaline phosphatase; ALT, alanine aminotransferase; AST, aspartate aminotransferase; BUN, blood urea nitrogen; Cl, chloride; CPK, creatinine phosphokinase; $\mathrm{Cr}$, creatinine; CRP, C-reactive protein; GCQID, glucosamine hydrochloride, chondroitin sulfate, quercetin glycosides, imidazole peptides, and vitamin D; $\gamma$-GTP, gamma-glutamyl transpeptidase; Hb, hemoglobin; HbA 1 , hemoglobin Al c; Hct, hematocrit; HDL-C, high-density lipoprotein cholesterol; K, potassium; LDH, lactate dehydrogenase; LDL-C, low-density lipoprotein cholesterol; Na, sodium; Plt, platelet; RBC, red blood cell; T-Bil, total bilirubin; TC, total cholesterol; TP, total protein; UA, uric acid; WBC, white blood cell.

Table S2 Incidence of adverse events ${ }^{\mathrm{a}}$

\begin{tabular}{lll}
\hline Variables & GCQID group & Placebo group \\
\hline Number of subjects eligible for safety assessment & 50 & 50 \\
Number of subjects with adverse events & 10 & 10 \\
Incidence of adverse events $^{\text {( } \%)}$ & 20 & 20 \\
Number of adverse events & 14 & 1.000 \\
\hline
\end{tabular}

Note: ancidence of adverse events $(\%)=100 \times$ number of subjects with adverse events/number of subjects eligible for safety assessment.

Abbreviation: GCQID, glucosamine hydrochloride, chondroitin sulfate, quercetin glycosides, imidazole peptides, and vitamin D.

\section{Publish your work in this journal}

Clinical Interventions in Aging is an international, peer-reviewed journal focusing on evidence-based reports on the value or lack thereof of treatments intended to prevent or delay the onset of maladaptive correlates of aging in human beings. This journal is indexed on PubMed Central, MedLine,

\section{Dovepress}

CAS, Scopus and the Elsevier Bibliographic databases. The manuscript management system is completely online and includes a very quick and fair peer-review system, which is all easy to use. Visit http://www.dovepress. com/testimonials.php to read real quotes from published authors. 